\title{
One-Carbon Oxidative Annulations of 1,3-Enynes by Catalytic C-H Functionalization and 1,4-Rhodium(III) Migration
}

\author{
Johnathon D. Dooley and Hon Wai Lamª]
}

\begin{abstract}
Rhodium(III)-catalyzed $\mathrm{C}-\mathrm{H}$ functionalization-oxidative annulations of aromatic substrates with 1,3-enynes that contain allylic hydrogen atoms cis to the alkyne are described. The key step in these reactions is an alkenyl-to-allyl 1,4-rhodium(III) migration to give electrophilic $\pi$-allylrhodium(III) species. Nucleophilic trapping of these species gives heterocycles such as benzopyrans, isobenzofuranones, and isoindolinones.
\end{abstract}

\section{Introduction}

1,4-Metal migration is a powerful process that enables the functionalization of remote $\mathrm{C}-\mathrm{H}$ bonds by relaying reactivity from one site to another. ${ }^{[1]}$ As such, this migration has been utilized in a diverse range of synthetic methods. ${ }^{[1-10]}$ Key to the continued growth of this field is the discovery of new types of 1,4-metal migration that open up previously inaccessible modes of reactivity.

During the development of new oxidative annulations of alkynes by catalytic $\mathrm{C}-\mathrm{H}$ functionalization, ${ }^{[11]}$ we reported the first examples of alkenyl-to-allyl 1,4-rhodium(III) migration of 1,3enynes that contain allylic hydrogen atoms cis to the alkyne (Scheme 1A). ${ }^{[5 a, b]}$ This process was used in the preparation of both heterocyclic ${ }^{[5 a]}$ and carbocyclic products. ${ }^{[5 b]}$ On the basis of deuterium transfer studies, the key 1,4-rhodium(III) migration step is proposed to occur by a concerted metalationdeprotonation of alkenylrhodium species $\mathbf{A}$ to give rhodacycle $\mathbf{B}$, followed by protonolysis to give $\sigma$-allylrhodium(III) species $\mathbf{C}$. ${ }^{[5 a, b]}$ Isomerization of $\mathbf{C}$ into electrophilic m-allylrhodium(III) species $\mathbf{D}$ or $\mathbf{E}$ (among other isomers) is followed by nucleophilic trapping with the $\mathrm{XH}$ directing group to give products of $(n+1)^{[5 a]}$ or $(n+3)^{[5 b]}$ annulation (products $\mathbf{F}$ and $\mathbf{G}$, respectively). ${ }^{[12]}$ This reactivity contrasts strongly with other rhodium(III)-catalyzed oxidative annulations of 1,3-enynes, in which the alkynyl moiety of the 1,3-enyne serves as a two-carbon annulation partner (Scheme 1B). ${ }^{[13,14]}$ The utility of the $(n+1)$ annulations was demonstrated principally with 2-aryl cyclic 1,3-dicarbonyl compounds, although five additional examples of other

[a] Dr. J. D. Dooley

EaStCHEM, School of Chemistry, University of Edinburgh

Joseph Black Building, The King's Buildings

David Brewster Road, Edinburgh EH9 3FJ (UK)

Prof. H. W. Lam

The GSK Carbon Neutral Laboratories for Sustainable Chemistry

University of Nottingham, Jubilee Campus, Triumph Road

Nottingham, NG7 2TU (UK)

and

School of Chemistry, University of Nottingham, University Park Nottingham, NG7 2RD (UK)

E-mail: hon.lam@nottingham.ac.uk

Homepage: http://www.nottingham.ac.uk/ pczhl/

Supporting information for this article is available on the WWW under http://www.

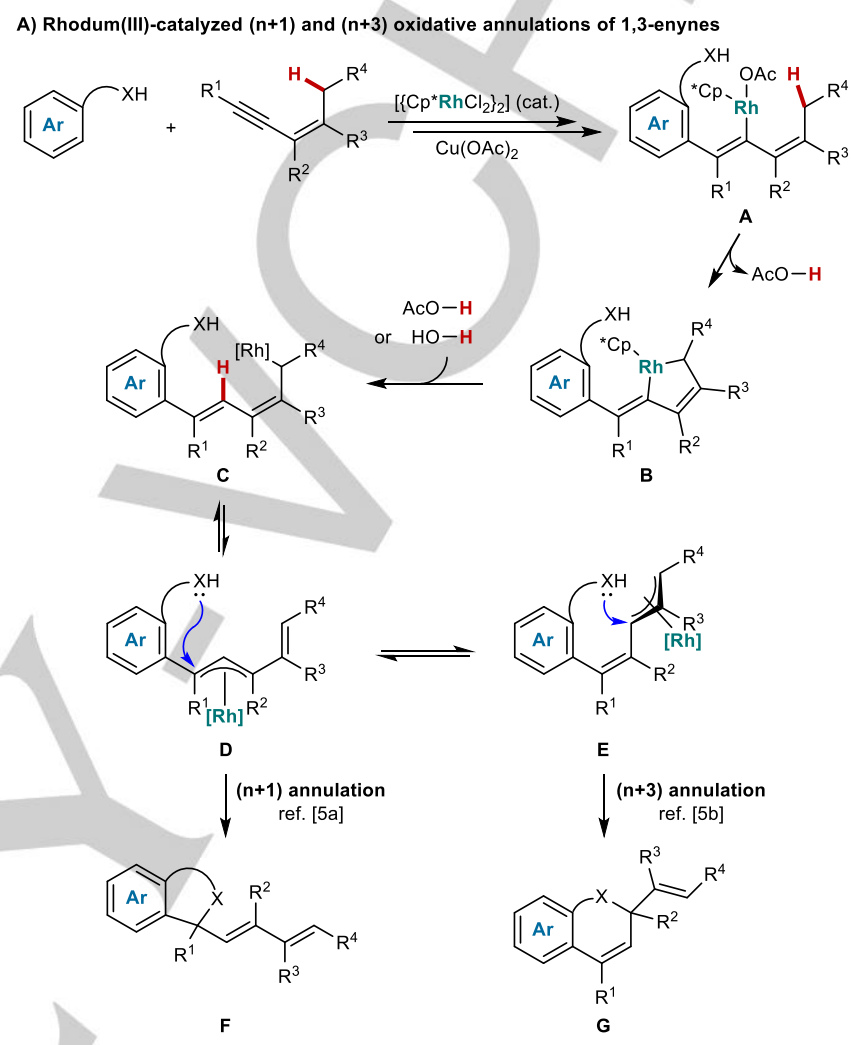

B) Rhodum (III)-catalyzed ( $n+2)$ oxidative annulations of 1,3-enynes (ref. 13)

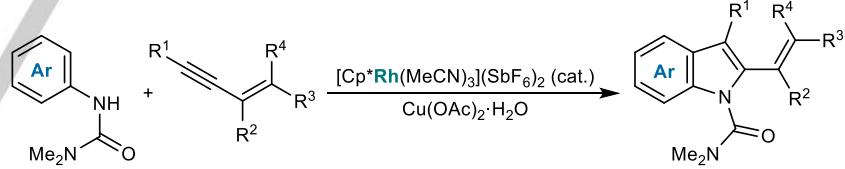

Scheme 1. Catalytic oxidative annulations of 1,3-enynes.

substrates with enol, phenol, carboxylic acid, or imide directing groups were also described. ${ }^{[5 a]}$ However, a more extensive investigation of these additional annulations was warranted to determine their scope and limitations. Herein, we describe a more thorough study of this process and demonstrate its applicability in the synthesis of a range of benzopyrans, isobenzofuranones, and isoindolinones.

\section{Results and Discussion}

Our studies began with the one-carbon oxidative annulations of 2-phenylphenol (2a) with 1,3-enynes $\mathbf{1 a}-\mathbf{1} \mathbf{h}$ (1.1 equiv) that contain allylic hydrogen atoms cis to the alkyne (Table 1). From a brief evaluation of reaction variables (see the Supporting Information), the best results were obtained using $\left[\left\{\mathrm{Cp}^{*} \mathrm{RhCl}_{2}\right\}_{2}\right]$ (3.0 mol\%) and $\mathrm{Cu}(\mathrm{OAc})_{2} \cdot \mathrm{H}_{2} \mathrm{O}\left(2.1\right.$ equiv) in dioxane at $120^{\circ} \mathrm{C}$. In addition, the inclusion of $\mathrm{K}_{2} \mathrm{CO}_{3}$ (3.0 equiv) was important for efficient reactivity, as extremely low conversions were observed in its absence. The reasons for this observation are not clear at the present time. Under these conditions, benzopyrans 3aa-3ac 
Table 1: Oxidative annulations of 2-phenylphenol with various 1,3-enynes. ${ }^{\text {[a] }}$

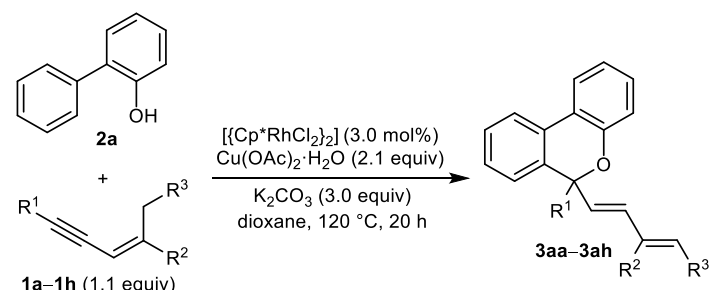

1a-1h (1.1 equiv)

1,3-Enynes<smiles>[R]C#CC=C(C)[N+]([O])([O])[O-]</smiles>

1a $\mathrm{R}=\mathrm{CH}_{2} \mathrm{CH}_{2} \mathrm{Ph}$

1b $\mathrm{R}=n \mathrm{~B}$

1c $\mathrm{R}=\left(\mathrm{CH}_{2}\right)_{3} \mathrm{OTBS}$

1d $\mathrm{R}=\left(\mathrm{CH}_{2}\right)_{3} \mathrm{OH}$

1e $\mathrm{R}=\mathrm{CH}_{2} \mathrm{NMe}_{2}$

\begin{tabular}{lll}
\hline Entry $1,3-E n y n e$ & Product & Yield [\%]
\end{tabular}

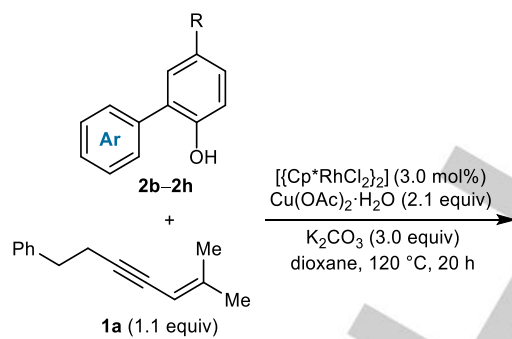

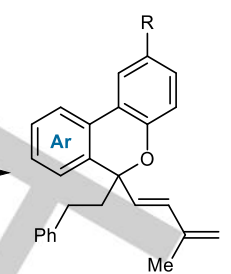

3ba-3ha<smiles>[R]c1ccc2c(c1)C(C=CC(=C)C)(CCc1ccccc1)Oc1ccccc1-2</smiles>

3ba $\mathrm{R}=\mathrm{Me}, 65 \%$

3ca $R=O M e, 70 \%$

3da $\mathrm{R}=\mathrm{Ac}, 87 \%$

3ea $\mathrm{R}=\mathrm{NO}_{2}, 47 \%[\mathrm{a}]$

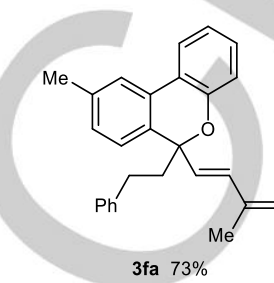

3 fa $73 \%$

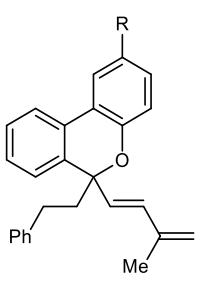

3ga $R=M e, 86 \%$
3ha $R=F, 86 \%$

Scheme 2. Reactions of various 2-arylphenols with 1,3-enyne 2a. Reactions were conducted with $0.50 \mathrm{mmol}$ of $\mathbf{2 b - 2 h}$. Yields are of isolated products. [a] Isolated as a $7.6: 1$ mixture of $E: Z$ isomers.

C-H functionalization at the sterically more accessible site to give benzopyran $\mathbf{3 f a}$ in $73 \%$ yield. Methyl or fluoride groups para- to the hydroxyl moiety of the phenol are also accommodated (3ga and 3ha).

Next, benzoic acid (4a) and $N$-acetylbenzamide (5a) were evaluated in reactions with a range of 1,3-enynes (Scheme 3 ). In these reactions, DMF is superior to dioxane, $\mathrm{K}_{2} \mathrm{CO}_{3}$ is unnecessary, and the temperature can be decreased to $100{ }^{\circ} \mathrm{C}$. Furthermore, the loading of $\left[\left\{\mathrm{Cp}^{*} \mathrm{RhCl}_{2}\right\}_{2}\right]$ was reduced to 1.0 mol\% and 1.5 mol\% for $\mathbf{4 a}$ and $\mathbf{5 a}$, respectively, and satisfactory results were maintained. Pleasingly, benzoic acid reacted smoothly with a range of 1,3-enynes to give isobenzofuranones

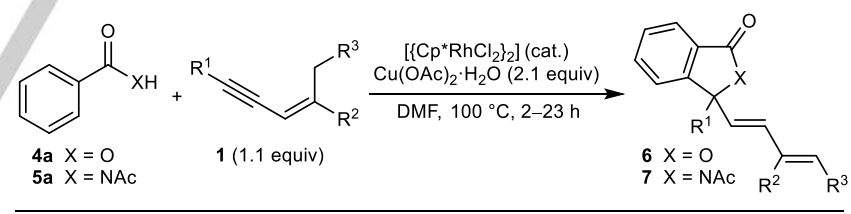

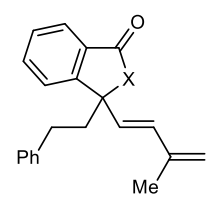

6aa $X=0,76 \%$ [a] 6aa $X=0,76 \%(a)$
7 aa $=$ NAc, $75 \%$<smiles>[X]C1(C=CC(=C)c2ccccc2)[X]C(=O)c2ccccc21</smiles>

6af $X=0,57 \%$ 6af $X=0,57 \%$
7af $X=N A C, 15 \%$

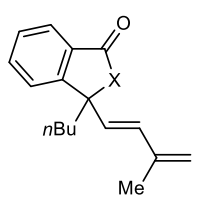

6ab $X=0,67 \%$ $7 a b X=$ NAc, $55 \%$<smiles>[X]C1(C=CC=C)CCc2ccccc21</smiles>

6ag X $=0,42 \%$
7 ag X $=$ NAc, $30 \%$

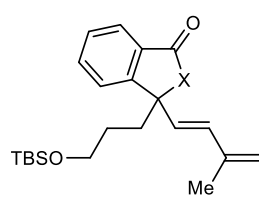

6ac $X=0,66 \%$ 7 ac $X=$ NAc, $54 \%$

Scheme 3. Reactions of benzoic acid (4a) or $N$-acetylbenzamide (5a) with various 1,3-enynes. Reactions with $\mathbf{4 a}$ were conducted using $1.0 \mathrm{~mol} \%$ of [ $\left.\left\{\mathrm{Cp}^{*} \mathrm{RhCl}_{2}\right\}_{2}\right]$, whereas $1.5 \mathrm{~mol} \%$ of $\left[\left\{\mathrm{Cp}^{*} \mathrm{RhCl}_{2}\right\}_{2}\right]$ was used in the reactions of 5a. [a] An isochromenone 8, resulting from two-carbon oxidative annulation, was also isolated in $13 \%$ yield (see the Supporting Information for the structure of $\mathbf{8}$ ). [b] Isolated as a 7:1 mixture of $E: Z$ isomers. 

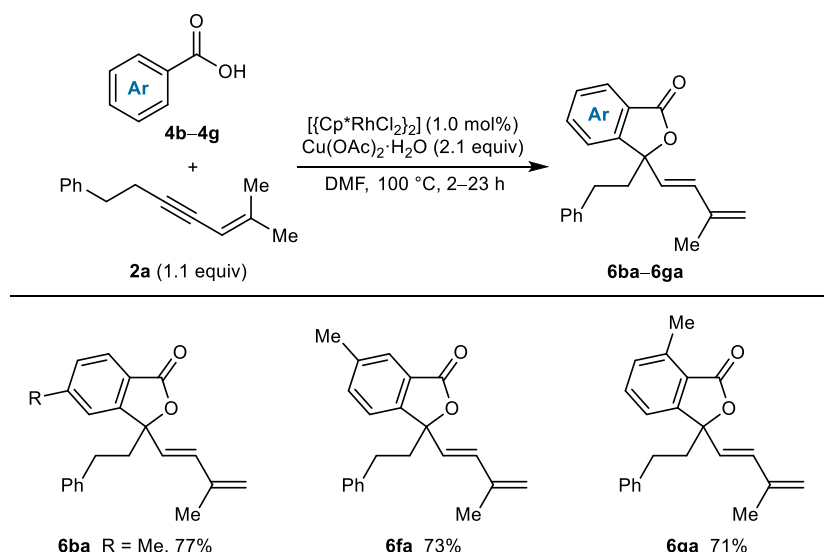

6ba $\mathrm{R}=\mathrm{Me}, 77 \%$

6 ca $\mathrm{R}=\mathrm{OMe}, 77 \%$

6ea $\mathrm{R}=\mathrm{NO}, 24 \%$

6ga $71 \%$

Scheme 4. Reactions of various benzoic acids with 1,3-enyne 2a. Reaction were conducted with $0.50 \mathrm{mmol}$ of $\mathbf{4 b} \mathbf{- 4 g}$.

6aa-6ac and 6 af-6ah in $42-77 \%$ yield. These reactions also gave small quantities of other products which could not be readily identified. However, in the reaction with 1,3-enyne 1a, isochromenone 8, resulting from two-carbon oxidative annulation, was isolated in $13 \%$ yield (see the Supporting Information). $\mathrm{N}$ Acetylbenzamide $(\mathbf{5 a})$ reacted with the same 1,3-enynes to give isoindolinones 7aa-7ac and 7af-7ah, although the yields were often appreciably lower than those of the corresponding reactions of benzoic acids. In the lower-yielding reactions, ${ }^{1} \mathrm{H}$ NMR analysis of the crude mixtures showed that in addition to the annulation products, residual 1,3-enyne and other unidentified products were present. Isoindolinone 7 ah was isolated as a $7: 1$ mixture of $E: Z$ isomers.

The scope of the process with respect to various benzoic acids was then investigated using 1,3-enyne 2a (Scheme 4). Electron-donating substituents such as methyl (6ba) or methoxy groups $(\mathbf{6 c a})$ at the para-position of the benzoic acid are
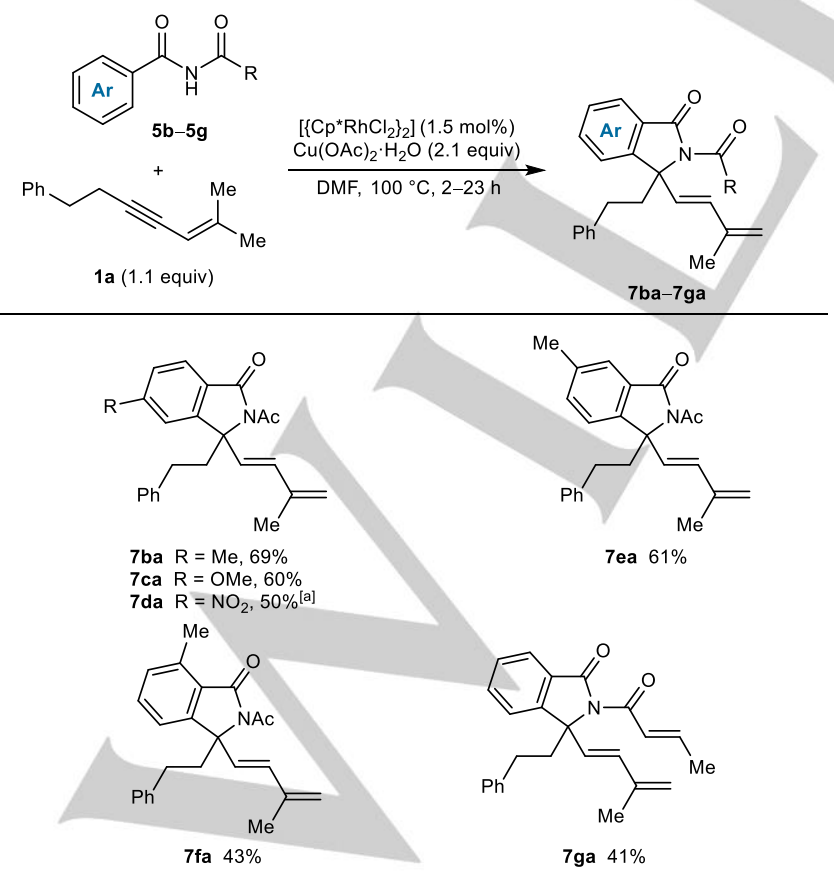

Scheme 5. Reactions of various $N$-acylbenzamides with 1,3-enyne 2a. Reactions were conducted with $0.50 \mathrm{mmol}$ of $\mathbf{5 b a}-\mathbf{5 g a}$. [a] Isolated as a $6.5: 1$ mixture of $E: Z$ isomers. tolerated, as is an electron-withdrawing nitrile group (6da). However, 4-nitrobenzoic acid is poorly effective and gave 6ea in only $24 \%$ yield, along with unreacted starting materials. Benzoic acids with a methyl group at the meta- or ortho-position are competent substrates (6fa and $\mathbf{6 g a}$ ), with $\mathrm{C}-\mathrm{H}$ functionalization occurring at the sterically less-hindered site in the case of $6 f a$.

The reactions of 1,3-enyne $2 \mathbf{a}$ with a range of $\mathrm{N}$ acylbenzamides gave results similar to those with the benzoic acids (Scheme 5, compare with Scheme 4). However, $\mathrm{N}$-acetyl4-nitrobenzamide is superior to 4-nitrobenzoic acid, as shown by the formation of isoindolinone $7 \mathrm{da}$ in $50 \%$ yield (albeit as a $6.5: 1$ mixture of $E: Z$ isomers). A substrate with an $\mathrm{N}$-crotonoyl substituent reacted successfully to give isoindolinone $7 \mathrm{ga}$ in $41 \%$ yield.

To confirm the structural requirements in the 1,3-enyne for efficient one-carbon annulation to occur, representative substrate 4a was reacted with 1,3-enyne 9, which lacks allylic hydrogen atoms cis to the alkyne [Eq. (1)]. ${ }^{1} \mathrm{H}$ NMR analysis of the crude mixture using an internal standard showed the formation of two-carbon annulation product $\mathbf{1 0}$ in
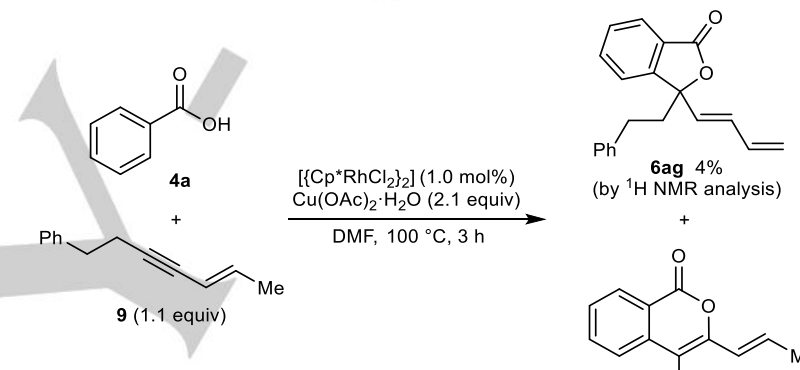
(by ${ }^{1} \mathrm{H}$ NMR analysis)

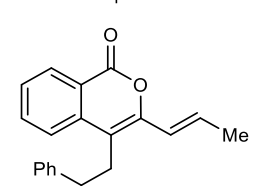

$1080 \%$ (by ${ }^{1} \mathrm{H}$ NMR analysis) $64 \%$ isolated

$80 \%$ yield, ${ }^{[16]}$ and isobenzofuranone 6 ag in $4 \%$ yield. Purification of the mixture led to isolation of 10 in $64 \%$ yield. This experiment demonstrates that allylic hydrogen atoms cis to the alkyne in the 1,3-enyne are important for efficient one-carbon annulation, which in turn provides further support for 1,4-rhodium(III) migration occurring through the intermediacy of rhodacycle $\mathbf{B}$ (Scheme 1A). The reasons for the formation of small quantities of one-carbon annulation product $\mathbf{6 a g}$ are not clear at this time, but may result from some type of $E / Z$ isomerization occurring during the reaction. ${ }^{[17]}$

\section{Conclusions}

We have reported rhodium(III)-catalyzed oxidative annulations of 2-arylphenols, benzoic acids, and $\mathrm{N}$-acylbenzamides with 1,3 enynes that contain allylic hydrogen atoms cis to the alkyne to give benzopyrans, isobenzofuranones, and isoindolinones, respectively. The key step in these reactions is the 1,4rhodium(III) migration from an alkenyl position to an allyl position, an allylic $\mathrm{C}-\mathrm{H}$ activation that constitutes an underexplored method to access electrophilic $\pi$-allylrhodium(III) species. ${ }^{[5 a, b]}$ This reactivity enables these 1,3-enynes to serve as one-carbon annulation partners rather than two-carbon annulation partners as might otherwise have been expected on the basis of literature precedent. ${ }^{[13]}$ These studies further demonstrate the utility of alkenyl-to-allyl 1,4-rhodium migration as a platform for novel 
reaction discovery. ${ }^{[3, \mathrm{k}, 5 \mathrm{ba}, \mathrm{b}]}$ Additional investigations in this area will be reported in due course.

\section{Acknowledgements}

This work was supported by the University of Edinburgh and the Engineering and Physical Sciences Research Council (grant numbers EP/I004769/1 and EP/I004769/2) through a Leadership Fellowship to H.W.L. We thank Dr. Rebecca E. Ruscoe (University of Nottingham) for assistance with control experiments.

\section{Conflict of Interest}

The authors declare no conflict of interest.

Keywords: catalysis - $\mathrm{C}-\mathrm{H}$ functionalization · enyne · isomerization $\cdot$ rhodium

[1] For reviews of 1,4-metal migration, see: a) S. Ma, Z. Gu, Angew Chem., Int. Ed. 2005, 44, 7512-7517. b) F. Shi, R. C. Larock, Top. Curr. Chem. 2009, 292, 123-164.

[2] For selected, recent examples of 1,4-palladium migration, see: a) J. Pan, M. Su, S. L. Buchwald, Angew. Chem., Int. Ed. 2011, 50, 8647 8651. b) H. J. Lee, K. H. Kim, S. H. Kim, J. N. Kim, Tetrahedron Lett 2013, 54, 170-175. c) T. Piou, A. Bunescu, Q. Wang, L. Neuville, J. Zhu Angew. Chem., Int. Ed. 2013, 52, 12385-12389. d) M. Wang, X. Zhang Y.-X. Zhuang, Y.-H. Xu, T.-P. Loh, J. Am. Chem. Soc. 2015, 137, 1341 1347. e) S. K. Bhunia, A. Polley, R. Natarajan, R. Jana, Chem. Eur. J. 2015, 21, 16786-16791. f) T.-J. Hu, G. Zhang, Y.-H. Chen, C.-G. Feng G.-Q. Lin, J. Am. Chem. Soc. 2016, 138, 2897-2900.

[3] For selected, recent examples of 1,4-rhodium(I) migration, see: a) K. Sasaki, T. Hayashi, Tetrahedron: Asymmetry 2012, 23, 373-380. b) T. Matsuda, Y. Suda, A. Takahashi, Chem. Commun. 2012, 48, 29882990. c) K. Sasaki, T. Nishimura, R. Shintani, E. A. B. Kantchev, T. Hayashi, Chem. Sci. 2012, 3, 1278-1283. d) J. Zhang, J.-F. Liu, A Ugrinov, A. F. X. Pillai, Z.-M. Sun, P. Zhao, J. Am. Chem. Soc. 2013, 135, 17270-17273. e) R. Shintani, R. lino, K. Nozaki, J. Am. Chem. Soc. 2014, 136, 7849-7852. f) H. B. Hepburn, H. W. Lam, Angew. Chem., Int Ed. 2014, 53, 11605-11610. g) T. Matsuda, S. Yasuoka, S. Watanuki, K. Fukuhara, Synlett 2015, 26, 1233-1237. h) T. Sawano, M. Hashizume, S. Nishimoto, K. Ou, T. Nishimura, Org. Lett. 2015, 17, 2630-2633. i) A. Masarwa, M. Weber, R. Sarpong, J. Am. Chem. Soc. 2015, 137, 63276334. j) B. M. Partridge, M. Callingham, W. Lewis, H. W. Lam, Angew. Chem., Int. Ed. 2017, 56, 7227-7232. k) M. Callingham, B. M. Partridge, W. Lewis, H. W. Lam, Angew. Chem., Int. Ed. 2017, 56, $16352-16356$.

[4] For stoichiometric 1,4-rhodium(III) migration, see: a) Y. Ikeda, K. Takano, S. Kodama, Y. Ishii, Chem. Commun. 2013, 49, 11104-11106. b) Y. Ikeda, K. Takano, M. Waragai, S. Kodama, N. Tsuchida, K. Takano, Y. Ishii, Organometallics 2014, 33, 2142-2145.

[5] For catalytic 1,4-rhodium(III) migration, see: a) D. J. Burns, H. W. Lam, Angew. Chem., Int. Ed. 2014, 53, 9931-9935. b) D. J. Burns, D. Best, M D. Wieczysty, H. W. Lam, Angew. Chem., Int. Ed. 2015, 54, 9958-9962. c) S. E. Korkis, D. J. Burns, H. W. Lam, J. Am. Chem. Soc. 2016, 138 12252-12257.

[6] For 1,4-cobalt migration, see: a) B.-H. Tan, J. Dong, N. Yoshikai, Angew. Chem., Int. Ed. 2012, 51, 9610-9614. b) B. Wu, N. Yoshikai, Angew. Chem., Int. Ed. 2013, 52, 10496-10499. c) B. Wu, M. Santra, N Yoshikai, Angew. Chem., Int. Ed. 2014, 53, 7543-7546. d) B.-H. Tan, N
Yoshikai, Org. Lett. 2014, 16, 3392-3395. e) J. Yan, N. Yoshikai, ACS Catal. 2016, 6, 3738-3742.

[7] For 1,4-nickel migration, see: A. L. Keen, M. Doster, S. A. Johnson, J. Am. Chem. Soc. 2007, 129, 810-819.

[8] For 1,4-iridium migration, see ref. [4b] and: a) B. M. Partridge, J. Solana González, H. W. Lam, Angew. Chem., Int. Ed. 2014, 53, 65236527. b) Y. Ikeda, S. Kodama, N. Tsuchida, Y. Ishii, Dalton Trans. 2015, 44, 17448-17452.

[9] For 1,4-ruthenium migration, see: K. Takano, Y. Ikeda, S. Kodama, Y Ishii, Chem. Commun. 2015, 51, 4981-4984.

[10] For 1,4-chromium migration, see: J. Yan, N. Yoshikai, Org. Chem. Front. 2017, 4, 1972-1975.

[11] For selected reviews of catalytic $\mathrm{C}-\mathrm{H}$ functionalization, see: a) $\mathrm{Z}$. Chen, B. Wang, J. Zhang, W. Yu, Z. Liu, Y. Zhang, Org. Chem. Front. 2015, 2, 1107-1295. b) P. Gandeepan, C.-H. Cheng, Chem. Asian. J. 2015, 10 , 824-838. c) J. Mo, L. Wang, Y. Liu, X. Cui, Synthesis 2015, 47, 439-459 d) G. Shi, Y. Zhang, Adv. Synth. Catal. 2014, 356, 1419-1442. e) N Kuhl, N. Schröder, F. Glorius, Adv. Synth. Catal. 2014, 356, 1443-1460. f) S. De Sarkar, W. Liu, S. I. Kozhushkov, L. Ackermann, Adv. Synth. Catal. 2014, 356, 1461-1479. g) L. Ackermann, Acc. Chem. Res. 2014, 47, 281-295. h) K. M. Engle, J.-Q. Yu, J. Org. Chem. 2013, 78, 89278955. i) K. M. Engle, T.-S. Mei, M. Wasa, J.-Q. Yu, Acc. Chem. Res 2012, 45, 788-802. j) C. S. Yeung, V. M. Dong, Chem. Rev. 2011, 111 1215-1292. k) J. Wencel-Delord, T. Droege, F. Liu, F. Glorius, Chem. Soc. Rev. 2011, 40, 4740-4761. I) L. Ackermann, Chem. Rev. 2011 111, 1315-1345. m) T. Satoh, M. Miura, Chem. Eur. J. 2010, 16, 11212 11222.

[12] For selected examples of the generation of electrophilic $\pi$-allylmeta species by allylic $\mathrm{C}-\mathrm{H}$ activation, see: a) S. Hansson, A. Heumann, T Rein, B. Aakermark, J. Org. Chem. 1990, 55, 975-984. b) D. J. Covell M. C. White, Angew. Chem., Int. Ed. 2008, 47, 6448-6451. c) N. A Vermeulen, J. H. Delcamp, M. C. White, J. Am. Chem. Soc. 2010, 132 11323-11328. d) B. M. Trost, D. A. Thaisrivongs, E. J. Donckele Angew. Chem., Int. Ed. 2013, 52, 1523-1526. e) T. J. Osberger, M. C White, J. Am. Chem. Soc. 2014, 136, 11176-11181. f) B. M. Trost, E. J. Donckele, D. A. Thaisrivongs, M. Osipov, J. T. Masters, J. Am. Chem Soc. 2015, 137, 2776-2784. g) Z.-L. Tao, X.-H. Li, Z.-Y. Han, L.-Z Gong, J. Am. Chem. Soc. 2015, 137, 4054-4057. h) P.-S. Wang, P. Liu Y.-J. Zhai, H.-C. Lin, Z.-Y. Han, L.-Z. Gong, J. Am. Chem. Soc. 2015 137, 12732-12735. I) S. E. Ammann, W. Liu, M. C. White, Angew. Chem., Int. Ed. 2016, 55, 9571-9575.

[13] M. P. Huestis, L. Chan, D. R. Stuart, K. Fagnou, Angew. Chem., Int. Ed. 2011, 50, 1338-1341.

[14] For rhodium(III)-catalyzed (5+1) oxidative annulations of arylguanidines with alkynes and 1,3-enynes, see: A. Cajaraville, J. Suarez, S. Lopez, J. A. Varela, C. Saa, Chem. Commun. 2015, 51, 15157-15160.

[15] In most cases, the Z-isomers were barely detectable in the ${ }^{1} \mathrm{H}$ NMR spectra of the crude reaction mixtures. However, small quantities of the $Z$-isomers were formed in the reactions producing 3ea (Scheme 2), 7ah (Scheme 3), and 7da (Scheme 5).

[16] For examples of rhodium(III)-catalyzed two-carbon oxidative annulations of benzoic acids with alkynes, see: a) K. Ueura, T. Satoh, M. Miura, Org. Lett. 2007, 9, 1407-1409. b) K. Ueura, T. Satoh, M. Miura, J. Org. Chem. 2007, 72, 5362-5367. c) Q. Li, Y. Yan, X. Wang, B. Gong, X. Tang, J. Shi, H. E. Xu, W. Yi, RSC Adv. 2013, 3, 23402 23408. d) L. Song, J. Xiao, W. Dong, Z. Peng, D. An, Eur. J. Org. Chem. 2017, 2017, 341-349.

[17] Performing the experiment shown in [Eq. (1)] but omitting benzoic acid (4a) led to the recovery of 1,3-enyne 9 with no evidence of $E / Z$ isomerization into 1,3-enyne $\mathbf{1 g}$ (see the Supporting Information). This observation suggests that if $E / Z$ isomerization of $\mathbf{9}$ into $\mathbf{1 g}$ occurs in the experiment shown in [Eq. (1)], benzoic acid is important in generating the species that promotes this isomerization. 
<smiles>[Y]CCc1ccccc1[Hg]</smiles><smiles>C=C(C)C=C(CCc1ccccc1)C1(CCc2ccccc2)Oc2ccccc2-c2ccccc21</smiles>

(with $\mathrm{K}_{2} \mathrm{CO}_{3}$ included)

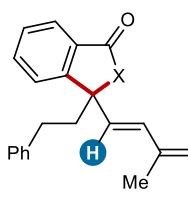

$\mathrm{X}=\mathrm{O}, \mathrm{NCOR}$

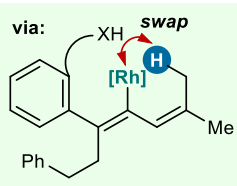

Can't wait to migrate: Rhodium(III)-catalyzed C-H functionalization-oxidative annulations of aromatic substrates with 1,3-enynes that contain allylic hydrogen atoms cis to the alkyne are described. The key step in these reactions is an alkenylto-allyl 1,4-rhodium(III) migration to give electrophilic m-allylrhodium(III) species, which are trapped to give benzopyrans, isobenzofuranones, and isoindolinones.

\section{J. D. Dooley, H. W. Lam*}

Page No. - Page No.

One-Carbon Oxidative Annulations of 1,3-Enynes by Catalytic $\mathrm{C}-\mathrm{H}$

Functionalization and 1,4-Rhodium(III) Migration 